\title{
NOMENCLATURAL STATUS OF THE GENERIC NAMES BALOGHIELLA BULANOVA-ZACHVATKINA, 1972 (ACARI) AND BALOGHIELLA MANDL, 1981 (COLEOPTERA)
}

\section{Bruce Halliday}

\author{
Australian National Insect Collection, CSIRO, Canberra, Australia
}

e-mail: bruce.halliday@csiro.au

KEY WORDS: Baloghiella, Oribatida, Coleoptera, generic names, nomenclatural status.

DOI: 10.21684/0132-8077-2019-27-1-113-114

Bulanova-Zachvatkina (1966) provided a brief review of the oribatid mite fauna of the USSR, mentioning the species Baloghiella prima. There is no description of the genus or species, so the generic name Baloghiella and the specific name prima are nomina nuda in that paper. Subsequent references to the name of this species as Baloghiella prima Bulanova-Zachvatkina, 1966 were incorrect (Balogh 1972; Balogh and Balogh 1992; Bayartogtokh and Akrami 2000; Akrami and Ebrahimi 2013).

Balogh (1972) provided morphological information about Baloghiella (Table 10.4, p. 129), included it in a key to genera, provided an illustration (pl. 52, fig. 5) and designated Baloghiella prima Bulanova-Zachvatkina as its type species ( $\mathrm{p}$. 169). He did not mention examining any specimens, so the source of Balogh's information about this species remains unknown. He attributed the generic name to Bulanova-Zachvatkina (pp. 129130). These actions make both names available, as Baloghiella Bulanova-Zachvatkina in Balogh, 1972, and Baloghiella prima Bulanova-Zachvatkina in Balogh, 1972. This point about authorship is explained in the International Code of Zoological Nomenclature, Article 50.1.1 (ICZN 1999).

Subías (2004) showed the authorship of $B a$ loghiella and B. prima as Bulanova-Zachvatkina, 1960. That is an error, which has been repeated in some databases (for example, ITIS 2007).

Two further species have been added to $\mathrm{Ba}$ loghiella since its description-Baloghiella granulata Bayartogtokh and Akrami, 2000 and $\mathrm{Ba}$ loghiella foveolata Akrami and Ebrahimi, 2013and the genus is now placed in the family Haplozetidae (Subías 2004).

The beetle genus Baloghiella Mandl, 1981 (Coleoptera: Cicindelidae) was described for the single species Baloghiella caledonica Mandl, 1981, based on a male specimen from New Caledonia (Mandl, 1981). Richoux et al. (2010) suggested that Baloghiella caledonica was probably a synonym of Vata thomsoni (Perroud and Montrousier, 1864), and this was confirmed by Deuve (2013). Baloghiella Mandl, 1981 is therefore a synonym of Vata Fauvel, 1881 (Fauvel 1881).

The generic name Baloghiella Mandl, 1981 is a junior homonym of Baloghiella Bulanova-Zachvatkina, 1972. Baloghiella Mandl, 1981 has no available junior synonyms. I, therefore, propose the name Vatiella nom. nov. as a substitute for Baloghiella Mandl, 1981. The name Vatiella is a hybrid of Vata and Baloghiella.

\section{ACKNOWLEDGEMENTS}

I would like to thank Joel Hallan and Roy Norton for bringing this problem to my attention and Thierry Deuve for his comments on the manuscript.

\section{REFERENCES}

Akrami, M.A. and Ebrahimi, F. 2013. A new species of the genus Baloghiella Bulanova-Zachvatkina, 1966 (Oribatida: Haplozetidae) from Iran. Systematic and Appled Acarology, 18: 396-400.

Balogh, J. 1972. The Oribatid Genera of the World. Akadémiai Kiadó, Budapest. 188 pp. + pls. 1-71.

Balogh, J. and Balogh, P. 1992. The Oribatid Mites Genera of the World. Hungarian Natural History Museum, Budapest, Vol. I, 263 pp., Vol. II, 375 pp.

Bayartogtokh, B. and Akrami, M.A. 2000. Poronotic oribatid mites (Acari: Oribatida: Poronota) from Iran. Journal of the Acarological Society of Japan, 9, 159-172.

Bulanova-Zachvatkina, E.M. 1966. On the fauna of oribatid mites of the USSR. In: B.E. Bykhovskii (Ed.). The First Acarological Congress. Abstracts of Presentations. Nauka, Moscow, pp. 44-45. [In Russian]

Deuve, T. 2013. Deux Cicindèles méconnues de Nouvelle-Calédonie (Coleoptera, Caraboidea). Bulletin de la Société Entomologique de France, 118: 241-242. 


\section{B. Halliday}

Fauvel, A. 1881. La note suivant. Bulletin des Séances de la Société Entomologique de France, Series 6, 1: cxvii.

ICZN. 1999. International Code of Zoological Nomenclature. $4^{\text {th }}$ edition. The International Trust for Zoological Nomenclature, London, $306 \mathrm{pp}$.

ITIS (Integrated Taxonomic Information System). 2007. ITIS Standard Report Page, Baloghiella Bulanova-Zachvatkina, 1960. https://www.itis.gov/ servlet/SingleRpt/SingleRpt?search_topic=TSN\& search_value $=734530 \#$ null $/$. Version dated 2007, accessed 20 May 2019.

Mandl, K. 1981. Neun neue Formen aus der Familie Cicindelidae aus fünf Kontinenten (Col.). Koleopterologische Rundschau, 55: 3-18.
Perroud, B.-P. and Montrousier, P. 1864. Essai sur la faune entomologique de Kanala (Nouvelle-Calédonie) et description de quelques espèces nouvelles ou peu connues. Annales de la Société Linnéenne de Lyon (N. S.), 11: 46-257 + 1 pl.

Richoux, P., Cassola, F., Cazeres, S. and Mille, C. 2010. Redescription de Vata gracilipes W. Horn, 1909, rare Cicindèle endémique de Nouvelle-Calédonie (Coleoptera, Cicindelidae). Bulletin de la Société Entomologique de France, 115: 281-284.

Subías, L.S. 2004. Listado sistemático, sinonímico y biogeográfico de los Ácaros Oribátidos (Acariformes: Oribatida) del mundo (1758-2002). Graellsia, 60 (Supplement): 3-305. 